\title{
Antimicrobial Activity and Rates of Tannins in Stryphnodendron adstringens Mart. Accessions Collected in the Brazilian Cerrado
}

\section{Giovana Maria Lanchoti Fiori ${ }^{{ }^{*}}$, Ana Lucia Fachin ${ }^{1}$, Valéria S. C. Correa ${ }^{2}$, Bianca Waleria Bertoni ${ }^{1}$, Silvana Giuliatti ${ }^{3}$, Saulo França Amui $^{3}$, Suzelei de Castro França ${ }^{1}$, Ana Maria Soares Pereira ${ }^{1}$}

${ }^{1}$ University of Ribeirão Preto-UNAERP, Ribeirão Preto, Brazil; ${ }^{2}$ Reserve EcoCerrado Brazil, Araxá, Brazil; ${ }^{3}$ Department of Genetics, University of São Paulo—USP, Ribeirão Preto, Brazil.

Email: "giovanalanchoti@gmail.com

Received September $2^{\text {nd }}, 2013$; revised October 20 $0^{\text {th }}, 2013$; accepted October 25 $5^{\text {th }}, 2013$

Copyright (C) 2013 Giovana Maria Lanchoti Fiori et al. This is an open access article distributed under the Creative Commons Attribution License, which permits unrestricted use, distribution, and reproduction in any medium, provided the original work is properly cited.

\begin{abstract}
Inner bark extracts of Stryphnodendron adstringens, a leguminous tree species known as Barbatimão, are often incorporated to phytotherapic formulations due to their antimicrobial and healing activities. In this study, extracts from $S$. adstringens accessions collected in 12 distinct locations were investigated in order to determine the rates of tannins in inner barks and to validate $S$. adstringens antibacterial and antifungal effectiveness. Yields of tannins were quantified by colorimetric assay following methodology described in the Brazilian Pharmacopoeia and the antimicrobial activity was determined by microdilution technique proposed by the National Committee for Clinical Laboratory Standards using S. adstringens hydroalcoholic and aqueous extracts and semi-purified fractions. Investigated extracts did not present significant antibacterial activity though aqueous extracts exhibited antifungal effect against both Trichophyton rubrum mutant and clinical strains (MIC $156 \mu \mathrm{g} / \mathrm{mL}$ ). A positive correlation between tannin concentration and antifungal activity was observed and the accessions collected in Delfinópolis (MG) were considered elite.
\end{abstract}

Keywords: Cerrado; Barbatimão; Genetic Diversity; Phytoterapy

\section{Introduction}

Stryphnodendron adstringens, a leguminous tree species endemic to the Cerrado (savanna biome) is popularly known as barbatimão and its inner bark extracts are traditionally used for ulcer and wound healing [1]. S. adstringens extract is rich in condensed tannins which are known to induce tissue repair [2].

Preclinical trials reported the regenerative action of $S$. adstringens inner bark aqueous extracts [3] and clinical trials validated $S$. adstringens healing action on pressure ulcers [4], leading to the development of an effectively commercialized phytopharmaceutical brand named Fitoscar $^{\circledR}$.

Several studies using $S$. adstringens inner bark extracts have reported their efficacy as anti-inflammatory in subacute and chronic models of inflammation [5], anti-

${ }^{*}$ Corresponding author. nociceptive [6], anti-protozoal [7] and antimicrobial [8].

Human infections caused by fungi and bacteria increased drastically in the last years. The treatment of mycosis is based on the therapy used against bacteria and antifungals, which are less prevalent if compared to antibacterial agents. Additionally, the therapeutics used against microorganisms is not always effective, causing resistance or recurrence, producing significant toxicity. The dermatophyte Trichophyton rubrum which usually causes well-characterized superficial mycosis acts as invasive in immunodepressed patients [9,10], reported the in vitro occurrence of a mutant of the T. rubrum (gri1) with a knock-out mutation in the ABC genes, that are drug sensitive and can be used to test new compounds with specific fungitoxicity [11].

Considering that the production of secondary metabolites in plants and the consequent therapeutic activity of a medicinal species are directly affected by its genetics, 
biotic and abiotic environmental conditions and by the interaction of all those aspects, the aim of this work was to quantify the concentration of tannins in 12 accessions of $S$. adstringens collected in 3 different states of Brazil and determine the antimicrobial activity of extracts from those accessions in order to identify prime regions for collecting source material for the production of phytopharmaceuticals.

\section{Plant Material}

Stems from $S$. adstringens accessions were collected in the cities of Paranapanema, Botucatu and Cristais Paulista (SP); Sacramento, Araxá, Delfinópolis, Lagoa Formosa and Luislândia (MG); Cristalina, Caldas Novas, Campo Alegre and São João da Aliança (GO), totalizing 223 individuals. All collection sites were georeferenced using Global Positioning System (GPS) (Figure 1). Inner barks of those stems were dried in oven at $45^{\circ} \mathrm{C}$ and ground to powder (40 mesh). Flowering stems were herborized and 2 exsiccates of each individual were deposited at the herbarium of the University of Ribeirão Preto
(Voucher n 272 - 718).

\section{Hydroalcoholic Extracts}

Pulverized plant material (10 g) was extracted with hydroalcoholic solution (100 mL - 7:3 v/v) by static maceration (15 days). The extract was then evaporated and lyophilized.

\section{Aqueous Extracts}

The aqueous extracts was prepared by decoction boiling $10 \mathrm{~g}$ of inner bark powder, of each S. adstringens accession, in $100 \mathrm{~mL}$ of distilled water for 3 minutes, following vacuum filtration and lyophilization.

\section{Fractionation}

The lyophilized aqueous crude extract was chromatographed on a Sephadex LH20 column eluted with ethanol (absolute or $50 \%$ ), methanol (absolute or $50 \%$ ) and acetone $(70 \%)$ gradient solvent system. Obtained fractions (186) were analyzed by thin layer chromatog-

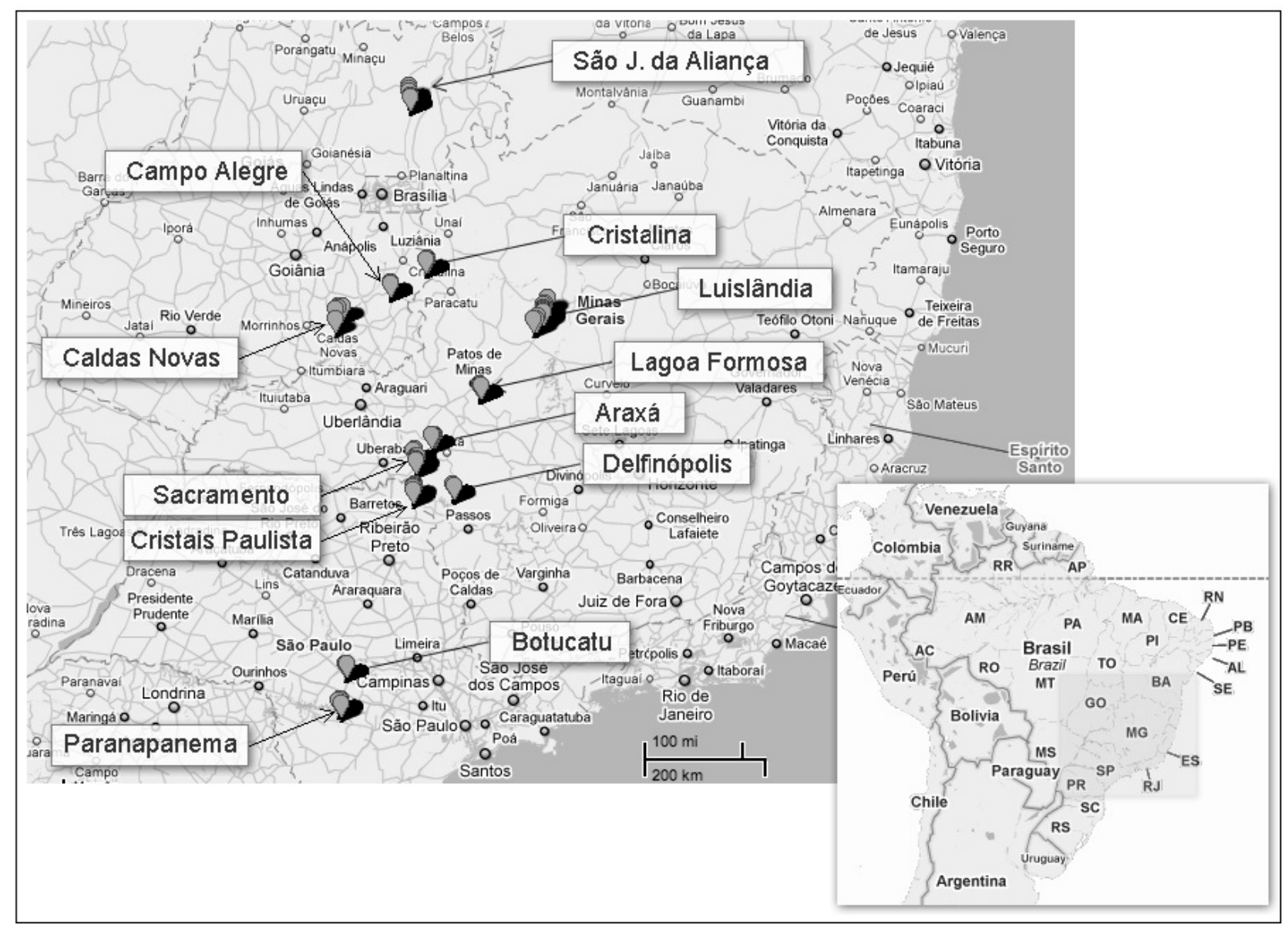

Figure 1. Brazilian Cerrado regions in the States of São Paulo, Minas Gerais and Goiás, sites of collection of S. adstringens accessions. 
raphy (TLC) and pooled according to their chemical profile in 3 fractions designated I, II and III, being the last the richer in tannin contents.

\section{Antifungal Assay}

A clinical Trichophyton rubrum isolate (ATCC-MYA3108) was obtained from a patient admitted to the UNAERP University Hospital in Ribeirão Preto, SP, Brazil. The mutant strain $\triangle$ TruMDR2 was obtained from disruption of the TruMDR2 gene from MYA3108 [12]. Standard techniques for microorganism manipulation and growth were previously described [10]. Susceptibility of the MYA3108 and $\Delta$ TruMDR2 mutant strains was tested by assessing the minimal inhibitory concentrations (MIC) values exhibited by different concentrations of aqueous extract and fractions of $S$. adstringens diluted in $10 \%$ dimethyl sulfoxide (DMSO) according to the M38-A microdilution technique proposed by the National Committee for Clinical Laboratory Standards (2002) [13]. The final concentration of DMSO, used in the antifungal assay was fixed at a maximum of $0.5 \%$. Microliter trays were incubated at $28^{\circ} \mathrm{C}$ and MICs were recorded after 7 days of incubation. The $\mathrm{MIC}_{100}$ was defined as the lowest concentration of the extract or fraction that completely inhibited the growth of fungal strains. The assays were carried out in three independent experiments performed in triplicate. Fluconazole (0.07 $\mathrm{mg} / \mathrm{mL}$ ) was used as reference control.

\section{Antibacterial Assay}

Staphylococcus aureus (ATCC 6538) and Escherichia coli (ATCC 25922) strains were used as test organisms. Antimicrobial activity against the ATCC strain was evaluated according to the microdilution method in a BHI medium [14]. Briefly, each experimental well containing different concentrations of crude extract and fractions diluted in $10 \%$ DMSO was inoculated with the bacterial suspension in a final concentration of 105 $\mathrm{CFU} / \mathrm{mL}$. DMSO final concentration for antifungal assay was fixed at a maximum of $0.5 \%$. Microdilution trays were incubated at $37^{\circ} \mathrm{C}$ and the MIC100, as defined above, was recorded after 24 hours of incubation. $\mathrm{MIC}_{100}$ was defined as the lowest concentration of the extract or fraction that completely inhibited the growth of bacterial strains. The assays were carried out in three independent experiments performed in triplicate. Ampicillin and chloramphenicol $(10 \mathrm{mg} / \mathrm{mL})$ were used as reference controls.

\section{Tannin Evaluation}

Tannin concentration was determined by modified colorimetric assay, absorbance wavelength at $750 \mathrm{~nm}$, as described in the Brazilian Pharmacopoeia [15] for S. adstringens cortex. Powdered bark ( $0.75 \mathrm{~g})$ was placed in a round-bottomed flask $(250 \mathrm{~mL})$ containing $100 \mathrm{~mL}$ of distilled water and heated for $30 \mathrm{~min}$ at $90^{\circ} \mathrm{C}-100^{\circ} \mathrm{C}$ temperature. After cooling under running water the extract was transferred to volumetric flask $(250 \mathrm{~mL})$ and the volume was completed with distilled water. After decantation, the solution was filtered through filter paper for three times.

\section{Statistical Analysis}

Experiments were conducted in a Completely Randomized Design (CRD), and the statistical analysis of obtained data was carried out using the software SISVAR, Federal University of Lavras, MG, Brazil, applying the F test to verify differences between treatments and the Scott-Knot test ( $p>0.05)$ for comparison of treatment means. Pearson's correlation was used to determine the correlation between concentration of tannins and minimal inhibitory concentrations (MIC).

\section{Results and Discussion}

MIC values determined for $S$. adstringens extracts indicated their significant antifungal activity. The MIC value obtained for aqueous crude extract was $56 \mu \mathrm{g} / \mathrm{mL}$ against both strains of $T$. rubrum. The fraction I presented higher antifungal activity for ATCC MYA3108 mutant strain and for $\Delta$ TruMDR2 wild strain $(312 \mu \mathrm{g} / \mathrm{mL}$ and 1250 $\mu \mathrm{g} / \mathrm{mL}$ respectively).

Obtained results indicate a synergic action among compounds present in S. adstringens crude extract that can enhance antifungal activity (Table 1). [16], reported similar results when testing the efficacy of $S$. adstringens extracts against different strains of the same microorganism.

The synergic effect of secondary metabolites found in plant crude extracts has been continuously demonstrated. [17] screening Plinia glomerata, a plant species as rich in phenolic compounds as $S$. adstringens, reported that $P$. glomerata crude extract showed more significant anti-

Table 1. MIC values $(\mu \mathrm{g} / \mathrm{mL})$ determined for aqueous extract and fractions from $S$. adstringens plants collected in Delfinópolis-MG against T. rubrum strains.

\begin{tabular}{ccc}
\hline Material & \multicolumn{2}{c}{ T. rubrum strains } \\
\hline & Mutant & MYA3108 \\
\hline Crude extract & 156 & 156 \\
Fraction I & 312 & 1250 \\
Fraction II & 62500 & 62500 \\
Fraction III & 1250 & 1250 \\
Fluconazole & 70 & 70 \\
\hline
\end{tabular}


fungal activity than the purified fractions or the pure compounds isolated from that plant.

With the exception of the accessions collected in Delfinópolis every other presented different MIC values for each individual and dissimilarities on tannin concentration were observed inter and intra plant populations. Considering the concentration of tannin the S. adstringens accessions were divided into 2 groups: the first group comprised individuals from Botucatu, Sacramento, Araxá, Lagoa Formosa, Cristalina, Caldas Novas and São João da Aliança which presented lower tannin rates $(21.76 \%$ to $28.34 \%$ ) and the individuals from Paranapanema, Cristais Paulista, Delfinópolis, Luislândia and Campo Alegre composed the second group which exhibited higher percentages of tannins (30.44\% to $37.09 \%$ ). Accordingly, all the investigated accessions presented superior rates of tannins considering the $8 \%$ minimum recommended by the Brazilian Pharmacopoeia [15].

The variation found in the accumulation of tannins in $S$. adstringens accessions may be related to both genetic diversity and edaphic characteristics. Soil collected in the natural habitat of the investigated accessions of $S$. adstringens was structurally different and according to [18] soil fertility directly influences the production of tannins in S. adstringens, being that populations native to less fertile soil accumulate higher amount of tannins.

S. adstringens collected in Delfinópolis (MG) presented higher rates of tannins and significant inhibition against T. rubrum strains (Table 2). Moreover it was observed that the greater the production of tannin, the lower was the volume of extract necessary for inhibiting mutant strain $\left(r^{2}=0.339\right.$; Figure 2) and wild strain $\left(r^{2}=\right.$ 0.259 ; Figure 3 ), those results confirm that tannins play a role on S. adstringens antifungal activity and that other compounds like flavonols and polymeric tannins isolated by [6] may comprise a synergic action that promote antifungal activity.

[16] reported three hypothesis that might explain the antimicrobial mechanism of tannins: inhibition of enzyme activity by complexation with substrates of bacteria and fungi; direct action of tannins on the microorganism metabolism, through the inhibition of oxidative phosphorylation; a mechanism involving the complexation of tannins with metabolic ions, decreasing the availability of essential ions to the metabolism of the microorganisms.

Regarding the antimicrobial activity of $S$. adstringens, the lyophilized crud extracts fro all investigated accessions showed no antibacterial activity against $S$. aureus (ATCC 6538) and E. coli (ATCC 25922) presenting MIC values $>10.000 \mu \mathrm{g} / \mathrm{mL}$. Similar results were reported by [19], investigating hydroalcoholic extract from a single $S$. adstringens plant against $E$. coli strain. However, as there are reports on the bactericidal effect of $S$. adstringens hydroalcoholic extract (96:4 v/v) against Staphylococcus aureus (ATCC 12692), Streptococcus mitis and Lactobacillus casei [16] it would be necessary additional investigations to validate $S$. adstringens bactericidal activity.

\section{Conclusions}

In this work the aqueous extract exhibited significant activity and it was observed a positive correlation between tannin production and antimicrobial action.

Plants collected in Delfinópolis, MG, presented higher rates of tannin and also greater inhibition against $T$. rubrum

Table 2. Rates of tannins and MIC values $(\mu \mathrm{g} \backslash \mathrm{mL})$ obtained for $S$. adstringens aqueous extracts against T. rubrum strains.

\begin{tabular}{|c|c|c|c|}
\hline \multirow{2}{*}{ Collection sites } & \multirow{2}{*}{ \% Tannin } & \multicolumn{2}{|c|}{ MIC T. rubrum fungal strains } \\
\hline & & Mutant & MYA3108 \\
\hline Araxá (MG) & $21.81 b$ & $351.56 a$ & $546.87 \mathrm{c}$ \\
\hline Botucatu (SP) & $28.34 b$ & $421.87 \mathrm{a}$ & 499.99b \\
\hline Caldas Novas (MG) & $27.34 b$ & $390.62 a$ & $468.75 b$ \\
\hline Campo Alegre (GO) & $30.80 \mathrm{a}$ & $304.68 a$ & $429.68 b$ \\
\hline Cristais Paulista (SP) & $30.44 \mathrm{a}$ & $440.62 \mathrm{a}$ & $625.00 b$ \\
\hline Cristalina (GO) & $21.76 b$ & 359.37a & $484.37 b$ \\
\hline Delfinópolis (MG) & $32.85 a$ & 249.98a & $273.42 \mathrm{a}$ \\
\hline Lagoa Formosa (MG) & $26.72 b$ & $888.88 \mathrm{c}$ & $343.75 a$ \\
\hline Luislandia (MG) & $37.09 \mathrm{a}$ & 381.94a & $425.34 b$ \\
\hline Paranapanema (SP) & $32.20 \mathrm{a}$ & $296.87 \mathrm{a}$ & $578.12 c$ \\
\hline Sacramento (MG) & $23.87 b$ & $507.81 \mathrm{a}$ & 359.65a \\
\hline São João da Aliança (GO) & $23.80 \mathrm{~b}$ & $687.50 \mathrm{~b}$ & $765.62 d$ \\
\hline
\end{tabular}

Means followed by the same letter do not statistically differ (Scott-Knott P > 0.05). Fluconazole $(70 \mu \mathrm{g} / \mathrm{mL})$ was used as reference control. 


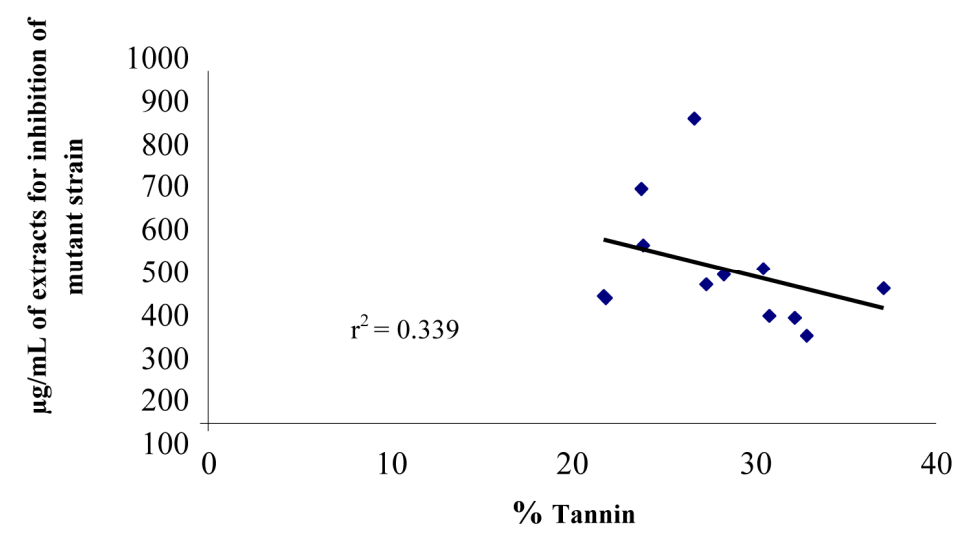

Figure 2. Correlation between tannin concentration and MIC values for $S$. adstringens extracts against $\Delta$ TruMDR2 T. rubrum mutant strain.

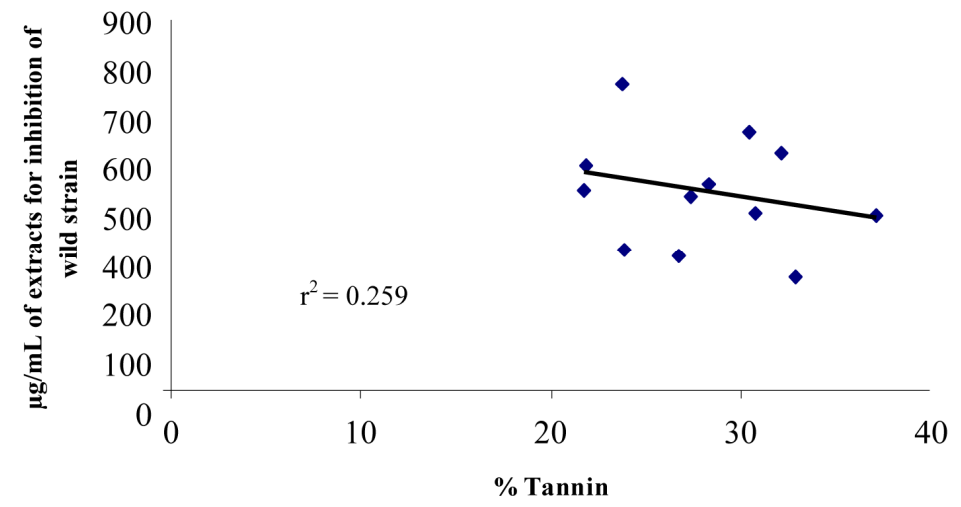

Figure 3. Correlation between tannin concentration and MIC values for S. adstringens extracts against MYA3108 T. rubrum strain.

strains, indicating the superiority of genotypes native to that region. Obtained results evidence that $S$. adstringens accessions from that population could be selected for genetic improvement programs and used as high-quality source material for the production of phytopharmaceuticals.

\section{Acknowledgements}

We thank the Fundação de Amparo à Pesquisa do Estado de São Paulo (FAPESP) for financial support (Process: 2008/00762-0; 2008/10499-4) and to Professor Nilce M. Martinez-Rossi for kindly providing the T. rubrum mutant strain.

\section{REFERENCES}

[1] S. Panizza, "Plants that Heal-Smell of the Woods," Ibrasa, São Paulo, 1998.

[2] G. C. Lopes, C. C. A. Sanches and C. V. Nakamura, "Influence of Extracts of Stryphnodendron polyphyllum Mart and Stryphnodendron obovatum Benth. On the Cicatrisation of Cutaneous Wounds in Rats," Journal of Ethnopharmacology, Vol. 99, No. 2, 2005, pp. 265-272.
[3] E. A. Audi, D. P. Toledo, P. G. Peres, E. Kimura, W. K. V. Pereira, J. C. P. De Mello, C. Nakamura, W. AlvesDo-Prado, C. A. Cuman and C. A. Bersani-Amado, "Gastric Antiulcerogenic Effects of Stryphnodendron adstringens in Rats,” Phytotherapy Research, Vol. 13, No. 3, 1999, pp. 264-266.

[4] D. G. Minatel, A. M. S. Pereira, T. M. Chiaratti, L. Pasqualin, J. C. N. Oliveira, L. B. Couto, R. C. C. Lia, J. M. Cintra, M. F. A. Bezzon and S. C. Franca, "Clinical Study for the Validation of the Efficacy of Ointment Containing Barbatimao (Stryphnodendron adstringens (Mart.) Coville on Healing of Decubitus Ulcers,” Brazilian Journal of Medicine, Vol. 67, 2010, pp. 250-256.

[5] J. C. S. Lima, D. T. Martins and J. R. P. T. Souza, "Experimental Evaluation of Stem Bark of Stryphnodendron adstringens (Mart.) Coville for Anti-Inflammatory Activity," Phytotherapy Research, Vol. 12, No. 3, 1998, pp. 218-220.

[6] J. O. Melo, T. H. Endo, L. E. Bersani-Amado, A. E. Svidzinski, S. Baroni, J. C. P. Mello and C. A. BersaniAmado, "Effect of Stryphnodendron adstringens (Barbatimão) Bark on Animal Models of Nociception,” Brazilian Journal of Pharmaceutical Sciences, Vol. 43, No. 3, 2007, pp. 465-469.

http://dx.doi.org/10.1590/S1516-93322007000300015 
[7] B. Holetz, T. Ueda-Nakamura, B. P. Dias Filho, J. C. Mello, J. A. Morgadodiaz, C. E. Toledo and C. V. Nakamura, "Biological Effects of Extracts Obtained from Stryphnodendron adstringens on Herpetomonas samuelpessoai," Memories of the Oswaldo Cruz Institute, Vol. 100, No. 4, 2005, pp. 397-401. http://dx.doi.org/10.1590/S0074-02762005000400010

[8] I. Ishida, J. C. De Mello, D. A. G. Cortez, B. P. Filho, T. Uedanakamura and C. V. Nakamura, "Influence of Tannins from Stryphnodendron adstringens on Growth and Virulence Factor of Candida albicans," Journal of Antimicrobial Chemotherapy, Vol. 58, No. 5, 2006, pp. 942949. http://dx.doi.org/10.1093/jac/dkl377

[9] C. Seebacher, J.-P. Bouchara and B. Mignon, "Updates on the Epiodermiology of Dermatophyte Infections," Mycopathologia, Vol. 166, No. 5-6, 2008, pp. 335-352. http://dx.doi.org/10.1007/s11046-008-9100-9

[10] A. L. Fachin, E. P. Contel and N. M. Martinez-Rossi, "Effect of Sub-MICs of Antimycotics on Expression of Intracellular Esterase of Trichophyton rubrum," Medical Mycology, Vol. 39, No. 1, 2001, pp. 129-133. http://dx.doi.org/10.1080/mmy.39.1.129.133

[11] A. C. Andrade, L.-H. Zwiers and M. A. de Waard, "Pesticide Chemistry and Bioscience,” G. T. Brooks and T. R., Eds., The Food-Environment Challenge, Royal Society of Chemistry, Cambridge, 1999, pp. 221-235. http://dx.doi.org/10.1533/9781845698416.5.221

[12] A. L. Fachin, M. S. Ferreira-Nozawa, J. R. W. Maccheroni and N. M. Martinez-Rossi, "Role of the ABC Transporter TruMDR2 in Terbinafine, 4-Nitroquinoline$\mathrm{N}-\mathrm{Oxide}$ (4NQO) and Ethidium Bromide Resistance in Trichophyton rubrum," Journal of Medical Microbiology, Vol. 55, No. 8, 2006, pp. 1093-1099. http://dx.doi.org/10.1099/jmm.0.46522-0

[13] National Committee for Clinical Laboratory Standards,
"Reference Method for Broth Dilution Antifungal Susceptibility Testing of Conidium-Forming Filamentous Fungi,” Proposed Standard, NCCLS Document M38-A, National Committee for Clinical Laboratory Standards, Wayne, 2002.

[14] National Committee for Clinical Laboratory Standards, "Methods for Dilution Antimicrobial Susceptibility Tests for Bacteria that Grow Aerobically," Approved Standard M7-A2, National Committee for Clinical Laboratory Standards, Villanova, 1990.

[15] Brazil. Ministry of Health National Health Surveillance Agency, "Resolution RDC 49, 23 November 2010. Approves the Brazilian Pharmacopoeia,” 5th Edition, Official Gazette, Brasília, 2010.

[16] V. R. Santos, R. T. Gomes, R. R. Oliveira, M. E. Cortes and M. G. L. Brandão, "Susceptibility of Oral Pathogenic Microorganisms to Aqueous and Ethanolic Extracts of Stryphnodendron adstringens (Barbatimão)," International Journal of Dentistry, Vol. 8, No. 1, 2009, pp. 1-5.

[17] C. Serafin, V. Nart, A. Malheiros, A. B. Cruz, F. D. Monache, M. A. Gette, S. Zacchino and V. Cechinel Filho, "Evaluation of the Antimicrobial Effects of Plinia glomerata (Myrtaceae)," Brazilian Journal of Pharmacognosy, Vol. 17, No. 4, 2007, pp. 578-582.

[18] T. K. B. Jacobson, J. Garcia, S. C. Santos, J. B. Duarte, J. G. Farias and H. J. Kliemann, "Influence of Edaphic Factors in the Production of Total Phenols and Tannins Two Barbatimão Species (Stryphnodendron sp.)," Tropical Agricultural Research, Vol. 35, No. 3, 2005, pp. 163-169.

[19] D. A. Oliveira, E. C. S. Junior, C. Castilho, J. V. Pereira, R. C. L. Pietro and M. D. Souza Neto, "Evaluation of the Antimicrobial Activity of Solutions of Sodium Hypochlorite at Different Concentrations and Barbatimão,” Journal Brazilian Phytomedine, Vol. 3, 2005, pp. 5-12. 